\title{
Benchmarking in Managing the Formation of Strategies for the Development of Agricultural Enterprises in the Region
}

\author{
Rogozina E.A. \\ National Research University of Information Technologies, \\ Mechanics and Optics (ITMO), \\ Saint Petersburg, Russia, \\ lelekin_96@mail.ru \\ Generalov I.G. \\ Nizhny Novgorod State University \\ of Engineering and Economics, \\ Knyaginino, Russia, \\ ivan.generalov.91@bk.ru
}

\author{
Suslov S.A. \\ Nizhny Novgorod State University \\ of Engineering and Economics, \\ Knyaginino, Russia, \\ nccmail4@mail.ru \\ Zavivaev S.N. \\ Nizhny Novgorod State University \\ of Engineering and Economics, \\ Knyaginino, Russia, \\ szavivaiev@bk.ru
}

\author{
Sibiryaev A.S. \\ Financial University under the Government of the Russian Federation, \\ Moscow, Russia, \\ gimu09@mail.ru
}

\begin{abstract}
The article highlights the problem of effective use of benchmarking as a promising direction in the process of managing the formation of strategies for the development of agricultural enterprises in our country. The purpose of the study is to determine the basic concepts of benchmarking, substantiate the difference between it and competitive analysis, present the classical types and principles of benchmarking, its objects, and also highlight the practical principles of using benchmarking in managing the formation of an agricultural enterprise development strategy. Based on theoretical research, the basic concepts of benchmarking are determined, the difference between it and competitive analysis is substantiated, the classical types and principles of benchmarking, its objects, as well as practical principles of use in managing the formation of a development strategy for an agricultural enterprise, taking into account the specifics of the agricultural sphere, are highlighted. An algorithm for the use of benchmarking is proposed, based on the methodology of "indicator analysis", a possible program of actions for eliminating the gaps in indicators according to the developed benchmarking model. In practice, the benchmarking testing of enterprise " $A$ " on the basis of the reporting and statistical information of benchmarking does not allow to fully form long-term strategies, therefore it is more effective to combine benchmarking with a methodically verified analysis of the external and internal environment. In the course of the study, the goals set by the team of authors were fully achieved.
\end{abstract}

Keywords-agrobusiness, benchmarking, agriculture, agricultural enterprise, management

\section{INTRODUCTION}

Agriculture is currently one of the most actively developing sectors of the economy for many countries of the world. It naturally forms part of the national strategies of states, in particular Russia. Today, farmers and state-owned enterprises are focused not only on everyday tasks - it is also extremely important to them to build sustainable development strategies that will ensure the competitiveness of their enterprises for many years to come, especially considering the dynamics of the global and regional markets, import substitution policies, sanctions instruments, dependence of production on natural factors, environmental friendliness, various types of competition, etc.

Problem Statement. It must be stated that the active introduction of benchmarking in our country is a matter of the future, not the present, meanwhile, its effective use allows us to get an answer not only to the question of how to achieve the set goals, but also to the question of determining the prospects for production and development. Benchmarking helps predict and plan strategic actions several steps ahead. We consider this a promising direction in the process of managing the 
formation of strategies for the development of agricultural enterprises.

The purpose of the study is to determine the basic concepts of benchmarking, substantiate the difference between it and competitive analysis, present the classical types and principles of benchmarking, its objects, and also highlight the practical principles of using benchmarking in managing the formation of an agricultural enterprise development strategy.

The successful functioning of the economy in the agrosphere involves a whole range of measures, which includes setting goals for the development of production, analyzing internal technological, organizational aspects, as well as external factors that affect the industry as a whole. Therefore, it is extremely important to select such methods of increasing the efficiency of production processes that can correspond to the specific goals of an individual agricultural enterprise. This strategy is benchmarking. The above factors determine its relevance precisely in the agricultural sphere.

Benchmarking, or comparative analysis, is the process of the most complete, systematic comparison of one company, the same amount of its processes with similar enterprises in a given sector of the economy or in a broad sense in relation to each type of product, process, function or even management approach (general "Focal points" for benchmarking initiatives include measures of time, quality, cost, manufacturability, efficiency, competitiveness, weaknesses, innovation, management, etc. along with customer satisfaction). We agree with V.N. Ostrovskaya, who emphasizes: "The concept of benchmarking is aimed at continuous improvement of the organization's activities and increasing its competitiveness by focusing on the highest achievements in all functional areas" [1]. In our opinion, the main difficulty of benchmarking as an approach lies in its structural multidimensionality, the need to cover and relate to each other a large number of segments. In addition, it should be borne in mind that we are not talking about traditional marketing research, not about any one-time events, but about strategic planning, which consists in the continuous implementation of a whole range of measures to improve production in conditions of their necessary operational correction.

L.G. Prus proposes a general classification of types of benchmarking based on fundamental features introduced into practice [2]:

- the level of management (micro, meso, macro level of benchmarking);

- evolution of development (reverse, competitive, process, strategic or global benchmarking);

- objects of influence (external or internal benchmarking);

- management style (strategic, tactical, operational benchmarking);

- subjects-participants (individual, partnership, system benchmarking);

- comparison characteristics (benchmarking costs, competitiveness, customer satisfaction, investment, innovation, etc.);

- the nature of the processes (benchmarking of the main or auxiliary processes, development processes, etc.).
The purpose of using benchmarking in business is to collectively compare a company's operations with those of competitors, and develop ideas for improving business processes, approaches and technologies to reduce costs, increase profits, and retain existing customers. In this regard, benchmarking has recently been considered in theory and implemented in practice as an important component of continuous improvement and quality initiatives.

\section{METHODS}

As for the origins, the main idea of benchmarking began to be introduced at the turn of the 19th-20th centuries: not everyone who is interested in the method knows that Henry Ford himself borrowed the idea of an automobile conveyor from a slaughterhouse. Actually, as a method, benchmarking has come into Western production since the 1900s. To date, a huge international experience has been accumulated. Over the 20 years from the end of the 20th century to the present day, interest in benchmarking has grown noticeably, this has been reflected in the information "field" a lot of English-language and translated publications, textbooks, monographs, articles, specialized Internet sites have appeared.

Among the foreign works covering various issues of the theory and practice of benchmarking, one can name a whole series of English-language publications by such researchers as R.C. Camp [3], D. Kahan [4], Spendolini [5], G.H. Watson [6], M. Zairi [7]. Harrington H.J.'s book "Benchmarking at its best", translated from English, has become famous [8]. It analyzed for the first time datasets of Ernst and Young benchmarking data for competing product procurement, product engineering analysis, manufacturing and business analysis.

\section{RESULTS AND DISCUSSION}

There is a point of view that the passion for comparative analysis is a peculiar sign of conservatism inherent in large companies: instead of introducing something new, they check what competitors are doing in a similar situation. Some even tend to call benchmarking "analysis paralysis". However, practice suggests otherwise. Comparative analysis is due to something other than the desire to simply copy someone else's experience as successfully as possible. Over time, best practices emerge in every sector of the business, based on the experience of which actions have led to successful results. They do not require copying, but the implementation of the "success algorithm" in new conditions [9; ten; eleven; 12]. At times, "collective wisdom" based on techniques that have worked before is the best the industry has to offer. This is especially important for those areas of business that are more affected by external factors, such as political processes, changes in the population structure or technological progress. Today, benchmarking is a developed methodology based on a system of "indicators" and "markers" of analysis in rating scales, a change management tool [8]. In the field of agricultural enterprises, this is primarily the quality of plant and animal products, crop productivity, profitability, milk yield, and live weight gain.

It is advisable to rely on the developed classification of benchmarking, carried out according to the following criteria [2]: by the level of management - benchmarking at the micro, meso and macro levels; development evolution - reversible, competitive, process, strategic and global; relative to the 
object of influence - external and internal; by the level of management - strategic, tactical and operational; by subjects associative, individual, partner, system; by characteristics of comparison - benchmarking of costs, competitiveness, customers, subject; for process control - benchmarking of main, auxiliary and development processes.

The choice of the method that an enterprise uses in the benchmarking process is largely dependent on what exactly will be assessed (process or performance results), in comparison with which the organization will evaluate its performance (other organizations, standards), as well as how it will use benchmarking (for continuous improvement or performance evaluation) [2].

Usually, competitive benchmarking is practiced, which is an analysis of the organization of the business of a competing enterprise in order to compare some aspects of the activities of enterprises and identify non-obvious processes that provide such an analysis, which gives a complete picture of the nature of the activities of the leaders of the competitive environment and the reasons for their success, since it concerns not only production and commercial aspects of activities, as well as psychological, in particular the psychological climate in a competitor's enterprise $[9,13,14]$.

There are some disadvantages to benchmarking. This is, first of all, the difficulty of obtaining real indicators due to the closed nature of enterprises. The systems of financial and tax accounting used in most cases do not always make it possible to see data for certain areas of activity.

Agricultural production is not monopoly, since a large number of small, medium and large enterprises operate in it, the demand for manufactured products exceeds supply, and the productivity of domestic production is low, therefore, the competitors of an agricultural enterprise when using benchmarking as a tool of strategic analysis may be a combination of regional enterprises or related specialization.

Benchmarking methods implementation plan:

1. Identification of areas of the company's activities that need analysis and improvement. For the analysis, one should know the features of the ongoing business processes.

2. Features of the benchmark company with which performance indicators should be compared. Indicators related to the main conditions of success in a competitive environment should be used as objects for comparison. Analysis of business processes of a company taken as a benchmark.

3. Comparison of the results of the study of the processes of one's own company with the results of the company used as a reference. Highlighting break points in the activities of our own and reference companies.

4. Determining how the benchmark company can achieve a high level of performance.

5. Setting performance standards for key aspects of the company that exceed the performance level of the reference company.

6. Identifying what needs to be done to bring the firm's performance to a better or even the same level as of the benchmark enterprise. Justification of current goals (here one should not copy the approaches of a competing company, since there is a possibility that the realities of companies may not correspond to the business environment, the nature of products and the market of each other).

7. Development of a plan for the implementation of the ideas received in order to bring the business in line with the standards and achieve superiority over them.

\section{Implementation of the planned plans.}

The benchmarking methodology provides that a comparative analysis with the production indicators of competitors is carried out according to predetermined socalled "analysis indicators" - generalized indicators given in a comparative rating scale. For agricultural enterprises, indicators can be generalizing indicators such as product quality, level of profitability, productivity, etc.

To assess these indicators, one can use 10,5 or a scale of assessments selected according to another criterion - both qualitative indicators and the number of indicators reduced to this scale: standard, actual or predicted [8].

It is clear that for a high-quality benchmarking test, one needs reliable information about the performance of competitors, as well as about one's own enterprise. With regard to agricultural enterprises, the most reliable and accessible is the reporting and statistical and primary accounting information, using which one can determine indicators for comparative analysis. In addition to this information, it is advisable to involve the results of surveys, observations, use other sources of obtaining sufficiently reliable information.

The number of indicators for analysis, the activities of agricultural enterprises should be limited, at the same time, they should fairly objectively assess the state of production, marketing, financial, investment and other specific activities of an agricultural enterprise. For example, we use a systematic approach to analyzing the environment of an agricultural enterprise, which is considered as an open system - "input", "converter", "output".

At the "exit" indicators of benchmarking testing will be the quantitative indicators of production resources. For agricultural enterprises, the main production resource is land, labor resources, as well as the means and objects of labor involved in the production process, that is, its assets.

To analyze the effectiveness of transformative (industrial agricultural activities), it is advisable to use generalizing indicators of costs and production costs of agricultural products by their types. At the "exit" of the corresponding products by their types. At the "exit", accordingly, choose indicators of financial activity - it is the indicator of the profitability of the sale of crop production.

We propose to consider in practice the benchmarking testing of the enterprise " $\mathrm{A}$ " of the region of the region on the basis of reporting and statistical information for the year. The type of economic activity of the enterprise is the cultivation of grain crops, the area of which is half hectares, the average number of employees is a person, the yield of grain is c/ha. Profit from the sale of grain, thousand, total cost of products sold - thousand, cost of 1 centner - rubles, the level of profitability $-\%$. 
The graph of the enterprise benchmarking profile is presented in Figure 1, we get three profile lines: 1) of the analyzed enterprise "A"; 2) with average values for the region or group of specialized enterprises; 3 ) with the best indicators of a leading enterprise in the industry, or with standard indicators. A five-point rating scale was used.

As can be seen from the graph, the enterprise is higher than the average for the district in terms of the analyzed indicators, but lower in some indicators of advanced enterprises. Only the prime cost of production had the highest score in our benchmarking test. We can conclude that the main strategy that the company under study now uses in its pricing policy is the strategy of average prices, because with a low cost of growing grain, it does not have the highest level of profitability in the region.

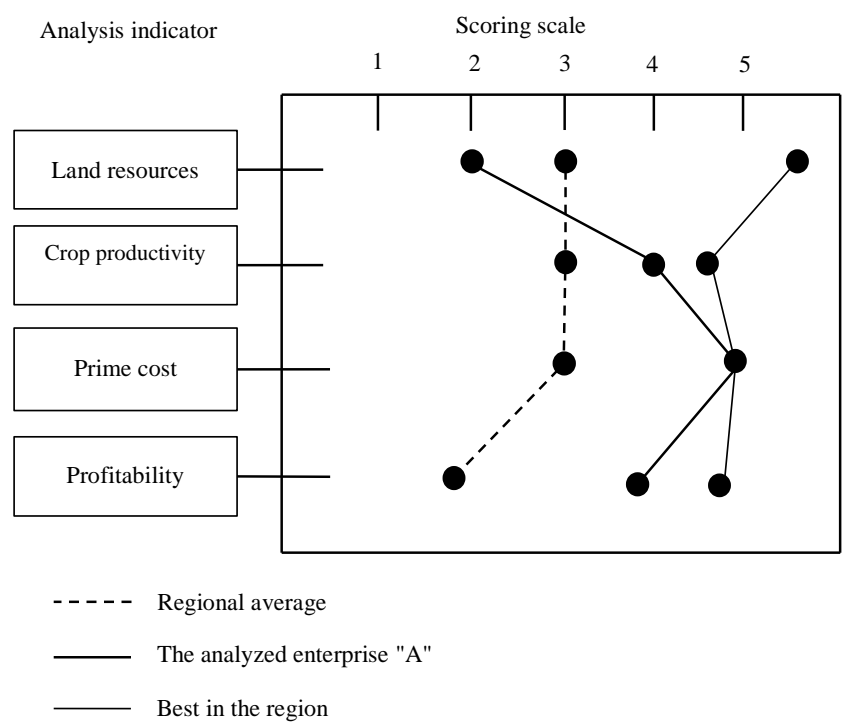

Fig. 1. Agricultural enterprise benchmarking profile

A plausible course of action to close the gaps according to the ICI fibers benchmarking model [3, 15] can be divided into the following categories:

1. To work better (the company concentrates its own forces and reaches the level of a competitor. At the same time, the organization works hard and therefore it is hardly possible to achieve success by urging those who are already making great efforts);

\section{Imitation (copying) of competitors;}

3. Direct ahead of competitors (based on data from other industries);

4. Changing the rules of the game on the market (the Program is used on condition that there is no possibility to act for reasons of economic and political nature. This requires a complete change in the strategy of activity (creation of a new product (service), conquering a new market segment, changing the target group of customers, etc)).

Within the framework of the analysis, we note that company $\mathrm{A}$ at this stage can choose a strategy to maintain its position in the market, a price leadership strategy or an offensive strategy in order to become a market leader. The choice of strategy should depend on many factors, starting with the global goal of the enterprise. It is also worthwhile to analyze in detail all other factors of the external and internal environment, using SWOT analysis, the BCG matrix, the McKingsey matrix and other scientifically based analysis methods.

As a result of intensive agricultural development, more food is being produced today than is needed for the entire population of the world, and at prices that have never been so low. Despite the apparent success, due to the impact of globalization and the growing pace of world trade, the agribusiness continues to often face uncertainty when formulating strategies for its enterprises. Changes in the people's diet, the strengthening of the trend for "healthy" food, technological progress - all these factors influence the decision-making process in the agricultural sector. In addition, one cannot ignore the global political situation - in recent years, relations between countries have had a tremendous impact on how farms have distributed their products. Millions of farmers every day think about what product to produce and how to produce it. The need to make such decisions presupposes a deep understanding of the situation in the agriculture sector as a whole, and competent benchmarking can help here.

The relevance of comparative analysis in the agricultural sector is beyond doubt. In many countries around the world, agricultural associations collect and publish industry benchmarks where information can be found for each agricultural product. Associations carry out a variety of research and have networks of local or regional chapters staffed by experts who provide evidence-based information for agricultural producers of all forms and for the public. In the foreground are reliable information of primary accounting, reporting and statistical, analytical information, which allows one to trace markers and indicators of growth, as well as, especially for consumers, surveys, observations, etc. This raises the question of the possibilities of obtaining information, difficulties, given the closed nature of certain positions of production.

Progressive agricultural producers, on the one hand, who do not even have to compete in the same geographic market, can benefit from communicating with each other and sharing information. However, they need to be careful to account for differences in costs, industry specifics, or supply and demand. An increasing number of agricultural producers are benefiting from participation in joint initiatives and the formation of expert advisory groups. This is one of the trends of our time.

While entry-level benchmarking is generally beneficial for all types of smallholder farmers, including those focused on local household demand, its practical use in agricultural business analysis will be more effective for commercially minded farmers who want to improve their profitability and competitiveness. Joining an existing benchmarking group or starting one's own is a great way to boost one's benchmarking performance.

\section{CONCLUSION}

To formulate a development strategy for an agricultural enterprise, it is proposed to apply the method of competitive analysis - benchmarking, the essence of which is a constant systematic search, the introduction of best practices in order to conduct effective activities. In the context of an open market 
and government policy, benchmarking can provide information on the common problems of enterprises in any industry and help find common ways to solve them. Benchmarking is useful for testing a strategy and helping to determine further strategic direction. However, the use of benchmarking alone does not allow to fully form long-term strategies, therefore, in our opinion, it is more effective to combine benchmarking with a methodically verified analysis of the external and internal environment.

\section{ACKNOWLEDGMENTS}

The team of the authors expresses gratitude for assistance in publishing the study to the Nizhny Novgorod State University of Engineering and Economics.

\section{REFERENCES}

[1] V.N. Ostrovskaya, "Global History of Benchmarking Development", Terra Economicus, 2009, vol. 7(2), pp. 266-271. (In Russ.).

[2] L.G. Prus, "Competitive management of higher educational institutions based on benchmarking", 2008.

[3] R.C. Camp, "Benchmarking," The Search for Industry Best Practices That Lead to Superior Performance, Wisconsin, ASQC Industry Press, Milwaukee, 1989.

[4] D. Kahan, "Farm business analysis using benchmarking", Farm management extension guide, 2010, vol. 4.

[5] M. Spendolini, "The Benchmarking Book”, N. Y., Amacom, 1992.

[6] G.H. Watson, "Strategic Benchmarking: How to Rate Your Company's Performance against the World's Best”, John Wiley \& Son, 1993.
[7] M. Zairi, "Effective Benchmarking: Learning from the Best", London, Chapman \& Hall, 1996.

[8] H.J. Harrington, "Benchmarking at his best. Lane from English", SPb: Peter, 2004.

[9] O.I. Sergienko, Yu.S. Suvorova, and T.A. Fedyushin, "Technological benchmarking to identify the best available technologies: a comparative analysis of European and Russian experience", Scientific Journal of NIU ITMO, 2015, vol. 3, pp. 414-428. (In Russ.).

[10] I. Generalov, S. Suslov, R. Bazhenov, E. Firsova, M. Shatalov, A. Igoshin and N. Shnarkina, "Economic Justification of the Territorial Grain Cluster", in Proceedings of the 33rd International Business Information Management Association Conference, Education excellence and innovation management through Vision 2020, 2019, pp. 4354-4360. (In Russ.).

[11] I. Generalov, S. Suslov, R. Bazhenov, A. Sibiryaev and O. Polivaeva, "Factors of growth of efficiency of grain production in the Nizhny Novgorod", in Proceedings of the Social and cultural transformations in the context of modern globalism (SCTCGM 2018), 2019, vol. 58, pp. 875-881. (In Russ.). https://dx.doi.org/10.15405/epsbs.2019.03.02.101

[12] E.F. Amirova, O.Y. Voronkova, K.A. Pyurveeva, M.A. Shatalov, T.A. Panteleeva and O.A. Sorokina, "Functioning of agroindustrial complex in the conditions of digital economy", International Journal of Mechanical Engineering and Technology, 2018, vol. 9(12), pp. 586-594. (In Russ.).

[13] E.G. Kovalenko, "Conceptual model of municipal strategy with a focus on spatial development", Bulletin NGIEI, 2020, vol. 6(109), pp. 75-87. (In Russ.).

[14] L.I. Zinina, A.A. Prokofieva, "Business Process Management Tools at Agribusiness Enterprises", Bulletin NGIEI, 2019, vol. 1(92), pp. 80-96. (In Russ.).

[15] D.A. Zyukin, "The place and role of grain farming in the effective implementation of the policy of import substitution of food products", Fundamental study, 2016, vol. 12(4). pp. 863-867. (In Russ.). 